\title{
Analysis of the Physical and Chemical Properties of Activated Carbons Based on Hulless Barley Straw and Plain Wheat Straw Obtained by $\mathrm{H}_{3} \mathrm{PO}_{4}$ Activation
}

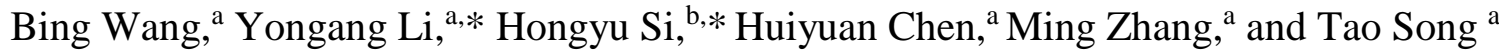

High specific surface area activated carbon was prepared by improving the process conditions of phosphoric acid activation and hulless barley straw and plain wheat straw as raw materials. The effects of the activation time on the pore structure and specific surface area of two types of activated carbon were investigated. The results revealed that soaking straws in the high concentrations of $\mathrm{H}_{3} \mathrm{PO}_{4}$ for $0.5 \mathrm{~h}$ to ensure complete soaking and then removing the straws from $\mathrm{H}_{3} \mathrm{PO}_{4}$ solution to activate was beneficial to the infiltration of $\mathrm{H}_{3} \mathrm{PO}_{4}$ in the raw material, and there was an increase in the surface area of activated carbon. The largest specific surface area of activated carbon prepared from plain wheat straw and hulless barley straw was $1524 \mathrm{~m}^{2} / \mathrm{g}$ and $1885 \mathrm{~m}^{2} / \mathrm{g}$, respectively. Thermogravimetric analysis and scanning electron microscopy showed that the higher cellulose content, higher hemicellulose content, and smaller fiber morphology in hulless barley straw compared with wheat straw were the main reasons for the more abundant pore structure and higher specific surface area of the activated carbon.
\end{abstract}

Keywords: Hulless barley straw; $\mathrm{H}_{3} \mathrm{PO}_{4}$ activation; Activated carbon; Activation time

Contact information: a: College of Chemical Engineering, Qinghai University, Xining 810016, China; b: Energy Institute of Shandong Academy of Sciences, Jinan, 250014, China;

*Corresponding authors: 18209712799@126.com, sihy@sderi.cn

\section{INTRODUCTION}

Activated carbon is widely used in adsorption storage, adsorption, separation, catalytic processes, supercapacitors, and other aspects of gas fuel due to its developed pore structure and large adsorption capacity (Bhaumik and Mondal 2015; Mashhadi et al. 2016a). The main raw materials used in preparing activated carbon are sawdust (Snyder et al. 2007), all types of coal (Hameed et al. 2007), coconut shell (Mao et al. 2014), agricultural waste (Mashhadi et al. 2016b), and some polymers (Guo et al. 2011). Studies on the preparation of activated carbon from hulless barley straw have been less reported. Hulless barley is a unique plant in the western plateau of China. Hulless barley straw is not suitable for power generation material and animal feed because of its lower heat and nutrition. A large amount of straw is usually used as fuel or returned directly to the field (Srivastava et al. 2006). The incomplete combustion and slow degradation of low temperature and hypoxia in the plateau results in the pollution of the local atmosphere and the acidification of soil (Fan et al. 2011). The preparation of activated carbon using hulless barley straw has alleviated the environmental pollution problem and provided a reasonable outlet for the utilization of the straw.

The raw material of activated carbon directly affects its physical and chemical properties. The main components of general biomass include hemicellulose, cellulose, 
lignin, water, extractives, and inorganic components (Huijgen et al. 2010). The content and structure are important factors affecting the physical and chemical properties of activated carbon. Hulless barley and wheat are gramineous plants (Tan et al. 2008). As a result of the different growth environments in plateaus and plains, hulless barley straw and wheat straw have different contents and morphologies of cellulose and hemicellulose (Ioannidou and Zabaniotou 2007). Therefore, the two types of straw-based activated carbon have different physical and chemical properties (Wu et al. 2014).

$\mathrm{H}_{3} \mathrm{PO}_{4}$ activation is a common method for the preparation of activated carbon due to its low energy consumption, low pollution, and high yield (Arvelakis et al. 2010). The raw material is usually mixed with different $\mathrm{H}_{3} \mathrm{PO}_{4}$ concentrations ranging from $30 \%$ to $60 \%$ in a certain impregnation ratio of 0.5 to 2.5 , and then activated at higher temperatures (Cui et al. 2015; Ghosh et al. 2016; Zhu et al. 2016). As the temperature rises, phosphoric acid depolymerizes the organic polymers (cellulose, hemicellulose, and lignin) of the raw material into small fragments, which form pores after washing. When the temperature is higher than $450{ }^{\circ} \mathrm{C}$, small molecule fragments lose protection due to loss of sublimation at a high temperature, resulting in shrinkage, which ultimately leads to a decrease in pore structure (Baquero et al. 2003). Compared with the method of activated carbon preparation activated by low concentration of phosphoric acid, increasing the concentration of phosphoric acid can shorten the activation time and reduce energy consumption (SuárezGarcia et al. 2001). However, immersing the raw material in a high concentration of phosphoric acid during the entire activation process will cause the reduction of specific surface area and yield of activated carbon (Jagtoyen and Derbyshire 1998). One view is that a high concentration of phosphoric acid solution will form a polyphosphate film to cover the developed pores (Hared et al. 2007); another view is that the high concentration of phosphoric acid, which tends to swell the raw material, makes the developing pores continue to expand and collapse (Montané et al. 2005).

However, for some raw material with a smaller density, its direct mixing makes the $\mathrm{H}_{3} \mathrm{PO}_{4}$ become mainly distributed on the bottom of the container, and a certain concentration gradient is formed longitudinally, causing the material to be impregnated unevenly (Yadav et al. 2013). Activated carbon prepared by this method has a lower specific surface area and yield.

In this study, hulless barley straw and plain wheat straw were soaked in highconcentration phosphoric acid for $0.5 \mathrm{~h}$ to ensure complete soaking and then removed from phosphoric acid to a convection oven for air drying and solidification. This method is conducive to the rapid and uniform penetration of phosphoric acid into the interior of the raw material while preventing the reduction of specific surface area caused by overactivation of phosphoric acid. The effects of the activation time on the pore structure and specific surface area of two types of activated carbon were studied.

\section{EXPERIMENTAL}

\section{Materials}

The hulless barley straw and wheat straw used were harvested from an average elevation of $2300 \mathrm{~m}$ (Qinghai, China) and $200 \mathrm{~m}$ (Shandong, China), respectively. The two types of straws were cut into $0.5 \mathrm{~cm}$ long segments, dried to a constant weight, and stored in a desiccator. 


\section{Methods}

\section{Preparation of activated carbon}

Hulless barley straw and wheat straw were soaked in an $80 \% \mathrm{H}_{3} \mathrm{PO}_{4}$ solution for $0.5 \mathrm{~h}$ and then removed to a convection oven at $140{ }^{\circ} \mathrm{C}$ for $1 \mathrm{~h}$. The activation of both mixtures was carried out in a laboratory muffle furnace under $\mathrm{N}_{2}$ flow. In the tubular furnace, the temperature was increased at approximately $5{ }^{\circ} \mathrm{C} / \mathrm{min}$ from room temperature to $450{ }^{\circ} \mathrm{C}$ and maintained at $450{ }^{\circ} \mathrm{C}$ for $0.5 \mathrm{~h}$ to $2.5 \mathrm{~h}$. Afterward, the two activated carbons were washed several times with deionized water, and $0.1 \mathrm{M} \mathrm{HCl}$ was added to remove ash byproducts. The products were washed with deionized water until $\mathrm{pH} 7$ was reached. The activated carbons were dried at $110{ }^{\circ} \mathrm{C}$ for $24 \mathrm{~h}$ and stored in a dryer. The activated carbons prepared using hulless barley straw and wheat straw were recorded as HAC-t and LAC-t, where " $\mathrm{t}$ " indicates the activation time in $\mathrm{h}$.

\section{Characterization of activated carbon}

The pore structure characteristics of the resulting carbons were determined by nitrogen adsorption at $-196{ }^{\circ} \mathrm{C}$ using an automatic ratio surface and aperture analyzer ( $3 \mathrm{~h}-$ 2000ps4, Bei Shi De, Beijing, China). Before the test, the activated carbon samples were degassed at $200{ }^{\circ} \mathrm{C}$ for $6 \mathrm{~h}$ to remove moisture and gas impurities. The surface area was determined by the Brunauer-Emmett-Teller (BET) method, and the pore diameter distribution was evaluated by the Barrett-Joyner-Halenda (BJH) method.

\section{RESULTS AND DISCUSSION}

As shown in Fig. 1, the pyrolysis of hulless barley straw and wheat straw is divided into four stages: drying and water loss, transition, rapid pyrolysis, and carbonization (Mall et al. 2005a, b). At a heating rate of $10 \mathrm{~K} / \mathrm{min}$, when the DTG curve showed the first weight loss peak, the hulless barley straw and wheat straw weight losses were $3.9 \%$ and $4.6 \%$, respectively, which was caused by the evaporation of the combined water in the straw. At the second weight loss peak of the DTG curve, the two curves fell sharply, and the hulless barley straw and wheat straw weight losses were $68.8 \%$ and $56.1 \%$, respectively. The cellulose and hemicellulose of the two types of straws rapidly decomposed in this stage.

(A)

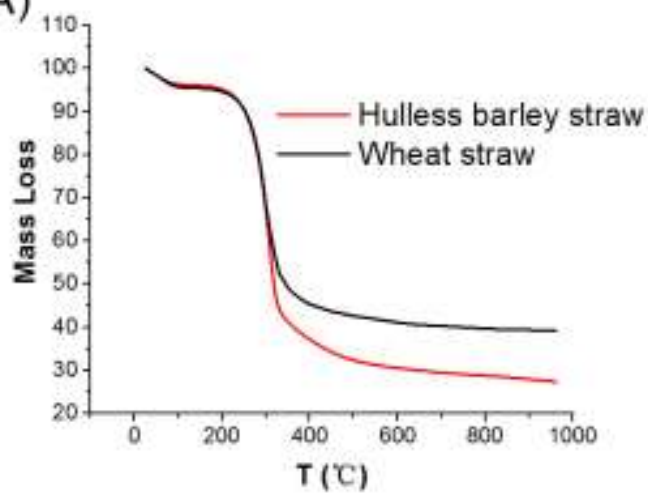

(B)

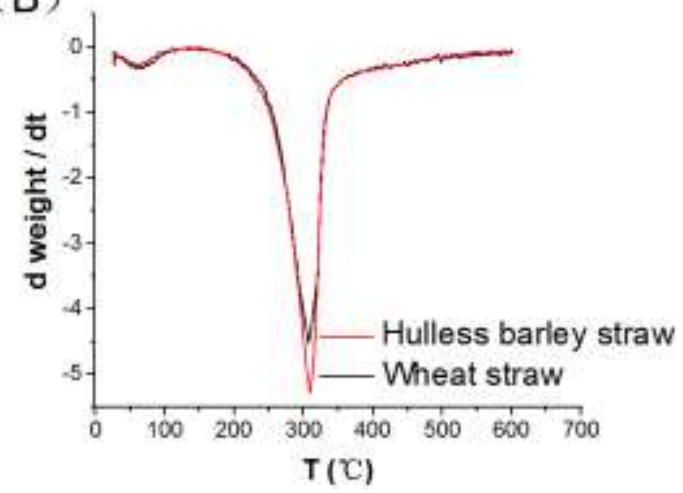

Fig. 1. The TG (A) - DTG (B) of hulless barley straw and wheat straw 
From the proportion of weight losses of the two types of straws, it was concluded that the content of cellulose and hemicellulose in hulless barley straw was higher than that in wheat straw. After the curve entered the carbonization stage, lignin slowly decomposed, the sample quality slowly decreased, and the curve was relatively gentle.

Table 1 shows the specific surface area of HAC and LAC at different activation times. Activated carbons were prepared with a specific surface area of $805 \mathrm{~m}^{2} / \mathrm{g}$ from wheat straw at $900{ }^{\circ} \mathrm{C}$ using $\mathrm{CO}_{2}$ activation (Zhang et al. 2014). Activated carbons were prepared with a specific surface area of $915 \mathrm{~m}^{2} / \mathrm{g}$ from hulless barley straw at $600{ }^{\circ} \mathrm{C}$ using zinc chloride activation (Ma et al. 2016). Activated carbons were prepared with a specific surface area of $1279 \mathrm{~m}^{2} / \mathrm{g}$ from wheat straw at $450{ }^{\circ} \mathrm{C}$ using $\mathrm{H}_{3} \mathrm{PO}_{4}$ activation ( $\mathrm{Lu}$ et al. 2011). The comparison revealed that $\mathrm{H}_{3} \mathrm{PO}_{4}$ activation had the advantages of low energy consumption and good activation effect. Compared with the activation method of directly mixing straw with low concentration of $\mathrm{H}_{3} \mathrm{PO}_{4}$, straws were soaked in a high concentration of $\mathrm{H}_{3} \mathrm{PO}_{4}$ and removed for activation, which is beneficial for the infiltration of $\mathrm{H}_{3} \mathrm{PO}_{4}$, increase of surface area, and yield of the activated carbon.

Table 1. Specific Surface Area, Pore Diameter, and Yield of Activated Carbon Products with Different Activation Times

\begin{tabular}{|c|c|c|c|}
\hline Sample Name & BET $\left(\mathrm{m}^{2} / \mathrm{g}\right)$ & Diameter $(\mathrm{nm})$ & Yield $(\%)$ \\
\hline HAC-0.5 & 1150 & 3.13 & 34.7 \\
\hline LAC-0.5 & 1389 & 3.57 & 31.4 \\
\hline HAC-1 & 1383 & 3.52 & 33.2 \\
\hline LAC-1 & 1533 & 3.96 & 28.4 \\
\hline HAC-1.5 & 1788 & 3.97 & 30.5 \\
\hline LAC-1.5 & 1435 & 4.21 & 25.6 \\
\hline HAC-2 & 1885 & 4.05 & 28.1 \\
\hline LAC-2 & 1321 & 4.56 & 23.2 \\
\hline HAC-2.5 & 1787 & 4.16 & 27.5 \\
\hline LAC-2.5 & 1241 & 4.85 & 21.6 \\
\hline
\end{tabular}

Table 1 shows that the extension of the activation time has different effects on the activated carbon produced using the hulless barley straw and plain wheat straw. In the activation time of $0.5 \mathrm{~h}$ to $1 \mathrm{~h}$, the specific surface area of LAC was higher than HAC. Since hulless barley is grown in plateaus with sufficient sunlight and oxygen deficits, the content of cellulose and hemicellulose in hulless barley straw is higher than that in plain wheat straw, and its fiber morphology is smaller and finer than that in plain wheat straw (Li et al. 2013). At the shorter activation time, it is difficult for this small fiber morphology to form a large number of pores, and some cellulose and hemicellulose have not been hydrolyzed. Only mesopores and macropores are formed in the external matrix. In contrast, the fiber morphology of plain wheat straw is relatively large, and the density is small. Thus, it is easier to form a large number of pores and obtain a higher specific surface area of activated carbon at the shorter activation time. However, as the activation time increased, the specific surface area of HAC gradually increased and the specific surface area of LAC gradually decreased. At the activation time of $2 \mathrm{~h}$, the specific surface area of HAC was $564 \mathrm{~m}^{2} / \mathrm{g}$ higher than LAC. A high concentration of $\mathrm{H}_{3} \mathrm{PO}_{4}$ through the external channel into the hulless barley straw fiber not only formed a large number of mesopores and macropores in the external matrix, but also formed a large number of micropores through the hydrolysis of cellulose and hemicellulose, thereby increasing the specific surface area rapidly. However, a high concentration of $\mathrm{H}_{3} \mathrm{PO}_{4}$ can enter the plain wheat straw fibers 
relatively quickly, and the activation process had been completed in about $1 \mathrm{~h}$. With the extension of activation time, the pores structure that formed was gradually corroded, resulting in the fusion of adjacent pore structures to form the larger pores structure, and reduced the development of the surface area and pores. When the activation time exceeded $2 \mathrm{~h}$, the activated carbon prepared by hulless barley straw also exhibited a decrease in specific surface area and an increase in pore size. As the activation time increased, the yield of the two types of activated carbons decreased. The yield of hulless barley straw-based activated carbons was higher than the plain wheat straw-based activated carbons, demonstrating that the hulless barley straw was an excellent biomass precursor for the preparation of porous activated carbons.

SEM was used to observe the surface morphology of activated carbon. As shown in Figs. 2A and 2B, at the activation time of $1 \mathrm{~h}$, the two activated carbons mostly exhibited micropore and mesopore structures. The surface of HAC-1 was relatively smooth, with only a slightly less visible pore structure, and the number of pores was significantly lower than LAC- 1 . Figure $2 \mathrm{C}$ shows that the elongation of the activation time made the pore diameter larger, the pore wall thinner, and the pores appeared looser, indicating that the interior of HAC-2 had an abundant porous structure. Figure 2D shows that the extension of the activation time caused the corrosion of the pores structure and disappearance of the pore wall of LAC-2. The pore diameter of the micropores increased rapidly, and the pores collapsed and fused to form the larger pores structure. Large-diameter impurities are apparent in Fig. 2D, indicating that excessive activation of the raw material by a highconcentration phosphoric acid solution formed polyphosphate that adhered to the activated carbon surface, thereby preventing the raw material from contacting the external environment. These impurities are difficult to remove during washing.
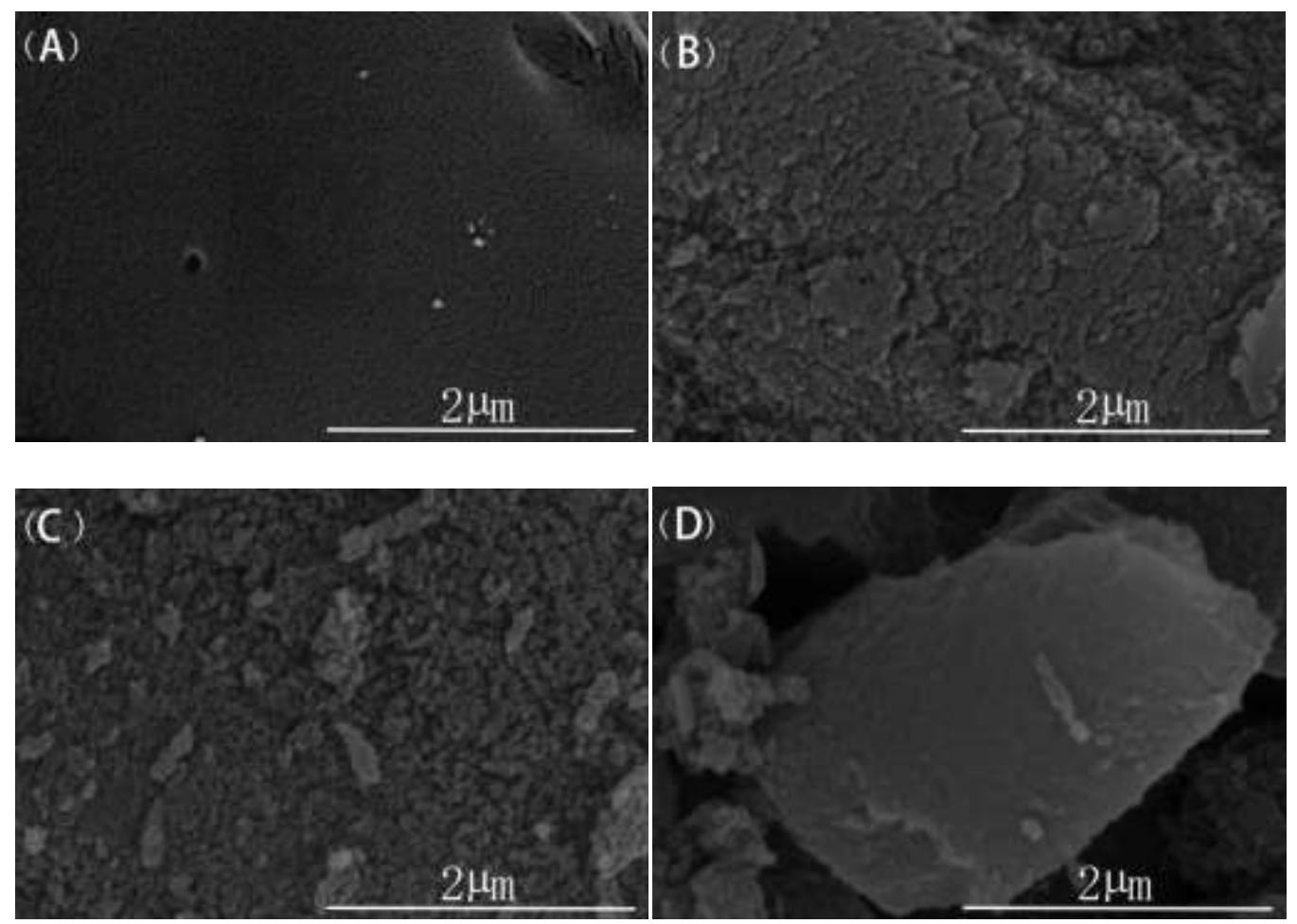

Fig. 2. SEM images of HAC-1 (A), LAC-1 (B), HAC-2 (C), and LAC-2 (D) 
Figure 3 shows the $\mathrm{N}_{2}$ adsorption isotherm curve for different activation times. The four isotherms belong to type IV as defined by the International Union of Pure and Applied Chemistry (IUPAC). When the relative pressure $P / P_{0}$ was low, the $\mathrm{N}_{2}$ adsorption increased rapidly, indicating the presence of micropores and the filling of micropores via adsorption. The point at $P / P_{0}=0.02$ indicated the saturation adsorption of the monolayer and that multilayer adsorption began at this stage. From the position of the inflection point, the numbers of micropores in $\mathrm{HAC}-1$ and LAC-1 were roughly the same. As the relative pressure $P / P_{0}$ increased, the adsorption capacity was not constant but increased slowly with a certain slope because of multilayer adsorption on non-micropores on the external surface (Rouquerol et al. 1999). Based on a comparison of the two adsorption curves in Fig. 3A, it was concluded that the mesopores and macropores of LAC-1 were more developed than HAC-1.

As shown in Fig. 3B, two samples exhibited typical characteristics of type IV adsorption isotherms. As shown in the adsorption isotherms of HAC-2, there was a significant increase at the point where the relative pressures $P / P_{0}=0.02$ and $P / P_{0}=0.8$, indicating that with the extension of time, the cellulose and hemicellulose of hulless barley straws were hydrolyzed into a large number of small molecules. These small molecules formed rich micropores and mesopores; moreover, a few macropores formed inside the activated carbon after washing. As shown in the adsorption isotherms of LAC-2, there was a significant reduction at the relative pressures $P / P_{0}=0.02$, demonstrating that some of the formed pores were blocked by the polyphosphate produced due to over-activation. At the same time, some developing pores formed mesopores and macropores under the action of high concentrations of phosphoric acid. Therefore, when the activation process had been completed, the extension of activation time resulted in the reduction of the specific surface area and the yield of activated carbon.

(A)

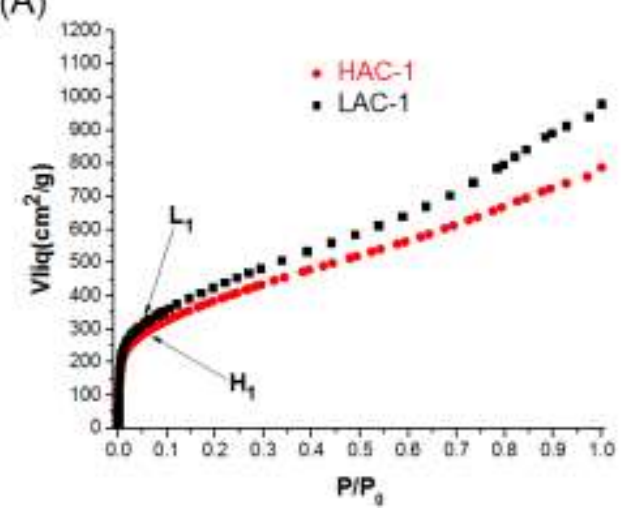

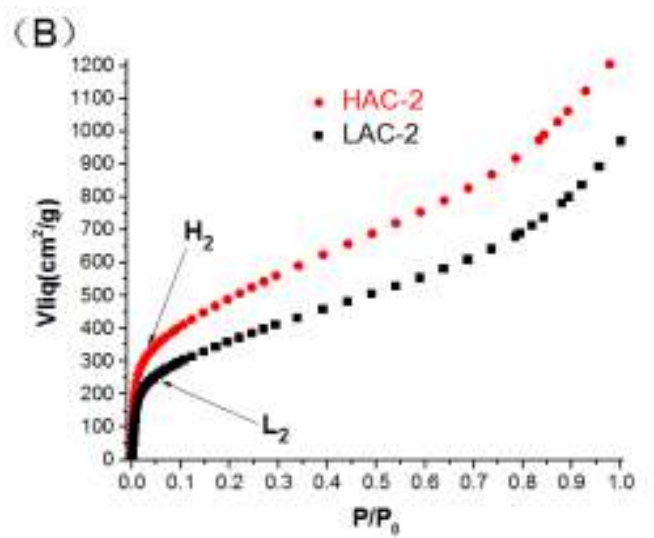

Fig. 3. $\mathrm{N}_{2}$ adsorption isotherms at $-196{ }^{\circ} \mathrm{C}$ on activated carbon in the activation time of $1 \mathrm{~h}(\mathrm{~A})$ and $2 \mathrm{~h}(\mathrm{~B})$

\section{CONCLUSIONS}

1. Compared with the activation method of directly mixing straw biomass with a low concentration of $\mathrm{H}_{3} \mathrm{PO}_{4}$ solution, the activation method of soaking straw in a high concentration of $\mathrm{H}_{3} \mathrm{PO}_{4}$ solution and removing the straw from $\mathrm{H}_{3} \mathrm{PO}_{4}$ solution to activate was beneficial to the infiltration of the $\mathrm{H}_{3} \mathrm{PO}_{4}$ solution, and abundant pores formed during the preparation of activated carbon. 
2. Activated carbons prepared using hulless barley straw had higher specific surface area attributed to the higher content of cellulose and hemicelluloses, and smaller fiber morphology than plain wheat straw, demonstrating that hulless barley straw was an excellent biomass precursor for the preparation of porous activated carbons.

\section{ACKNOWLEDGMENTS}

This work was supported by the Special Fund for Agro-Scientific Research in the Public Interest (Grant No. 201503135-04).

\section{REFERENCES CITED}

Arvelakis, S., Crocker, C., Folkedahl, B., Pavlish, J., and Spliethoff, H. (2010). "Activated carbon from biomass for mercury capture: Effect of the leaching pretreatment on the capture efficiency," Energy Fuels 24(3), 4445-4453.

DOI: $10.1021 / \mathrm{ef} 900613 \mathrm{~b}$

Baquero, M. C., Giraldo, L., Moreno, J. C., Suárez-GarcıA, F., MartıNez-Alonso, A., and Tascón, J. (2003). "Activated carbons by pyrolysis of coffee bean husks in presence of phosphoric acid," Journal of Analytical \& Applied Pyrolysis 70(2), 779-784. DOI: 10.1016/S0165-2370(02)00180-8

Bhaumik, R., and Mondal, N. K. (2015). "Adsorption of fluoride from aqueous solution by a new low-cost adsorbent: Thermally and chemically activated coconut fibre dust," Clean Technologies and Environmental Policy 17(8), 2157-2172. DOI: 10.1007/s10098-015-0937-6

Cui, J., Cui, L., Cheng, F., Liu, L., Sun, H., and Li, S. (2015). “A green route for preparation of low surface area $\mathrm{SiO}_{2}$ microspheres from wheat straw ash with activated carbon and NPK compound fertilizer as by-products," RSC Advances 5(98), 80238-80244. DOI: 10.1039/C5RA14622D

Fan, Z., Yan, J., Wei, T., Zhi, L., Ning, G., Li, T., and Wei, F. (2011). “Asymmetric supercapacitors based on graphene/ $\mathrm{MNO}_{2}$ and activated carbon nanofiber electrodes with high power and energy density," Advanced Functional Materials 21(12), 23662375. DOI: 10.1002/adfm.201100058

Ghosh, S. B., Bhaumik, R., and Mondal, N. K. (2016). "Optimization study of adsorption parameters for removal of fluoride using aluminum impregnated potato plant ash by response surface methodology," Clean Technologies and Environmental Policy 18(4), 1069-1083. DOI: 10.1007/s10098-016-1097-z

Guo, B., Li, X. G., Liu, R. P., and Ren, A. L. (2011). "Study of the preparation of activated carbon by using urban sludge mixed with wheat straws," Journal of Engineering for Thermal Energy and Power 26(6), 764-767.

Hameed, B. H., Din, A. T., and Ahmad, A. L. (2007). "Adsorption of methylene blue onto bamboo-based activated carbon: kinetics and equilibrium studies," Journal of Hazardous Materials 141(3), 819-25. DOI: 10.1016/j.jhazmat.2006.07.049

Hared, I. A., Dirion, J. L., Salvador, S., Lacroix, M., and Rio, S. (2007). "Pyrolysis of wood impregnated with phosphoric acid for the production of activated carbon: kinetics and porosity development studies," Journal of Analytical \& Applied Pyrolysis 79(1), 101-105. DOI: 10.1016/j.jaap.2006.12.016 
Huijgen, W. J. J., Reith, J. H., and Uil, H. D. (2010). "Pretreatment and fractionation of wheat straw by an acetone-based organosolv process," Industrial and Engineering Chemistry Research 49(20), 10132-10140. DOI: 10.1021/ie101247w

Ioannidou, O., and Zabaniotou, A. (2007). "Agricultural residues as precursors for activated carbon production: A review," Renewable and Sustainable Energy Reviews 11(9), 1966-2005. DOI: 10.1016/j.rser.2006.03.013

Jagtoyen, M., and Derbyshire, F. (1998). "Activated carbons from yellow poplar and white oak by $\mathrm{H}_{3} \mathrm{PO}_{4}$ activation," Carbon 36(7-8), 1085-1097. DOI: 10.1016/S00086223(98)00082-7

Li, Y. K., Wang, Y. D., Zhang, Y., Han, R. P., and Li, Y. Q. (2013). "Adsorption of 4chlorophenol onto activated carbon prepared from wheat straw: Equilibrium study," Applied Mechanics and Materials 319, 245-248. DOI: 10.4028/www.scientific.net/AMM.319.245

Lu, C. X. (2011). "Preparation and characterization of activated carbon from wheat straw," Journal of Anhui Agricultural Sciences 39(7), 4162-4164.

Ma, Y. (2016). "Comparison of activated carbons prepared from wheat straw via $\mathrm{ZNCl}_{2}$, and KOH activation," Waste and Biomass Valorization, 68(10), 298-305.

Mall, I. D., Srivastava, V. C., Agarwal, N. K., and Mishra, I. M. (2005a). “Adsorptive removal of Malachite green dye from aqueous solution by bagasse fly ash and activated carbon-Kinetic study and equilibrium isotherm analyses," Colloids and Surfaces A Physicochemical and Engineering Aspects 264(1-3), 17-28. DOI: 10.1016/j.colsurfa.2005.03.027

Mall, I. D., Srivastava, V. C., Agarwal, N. K., and Mishra, I. M. (2005b). "Removal of congo red from aqueous solution by bagasse fly ash and activated carbon-Kinetic study and equilibrium isotherm analyses," Chemosphere 61(4), 492-501. DOI: 10.1016/j.chemosphere.2005.03.065

Mao, H., Zhou, D., Hashisho, Z., Wang, S., Chen, H., and Wang, H. (2014). "Preparation of pinewood- and wheat straw-based activated carbon via a microwave-assisted potassium hydroxide treatment and an analysis of the effects of the microwave activation conditions," BioResources 10(1), 809-821. DOI: 10.15376/biores.10.1.809821

Mashhadi, S., Sohrabi, R., Javadian, H., Ghasemi, M., Tyagi, I., and Agarwal, S., et al. (2016a). "Rapid removal of hg (ii) from aqueous solution by rice straw activated carbon prepared by microwave-assisted $\mathrm{H}_{2} \mathrm{SO}_{4}$, activation: Kinetic, isotherm and thermodynamic studies," Journal of Molecular Liquids 215, 144-153. DOI: 10.1016/j.molliq.2015.12.040

Mashhadi, S., Javadian, H., Ghasemi, M., Saleh, T. A., and Gupta, V. K. (2016b). "Microwave-induced $\mathrm{H}_{2} \mathrm{SO}_{4}$ activation of activated carbon derived from rice agricultural wastes for sorption of methylene blue from aqueous solution," Desalination \& Water Treatment 57(44), 21091-21104. DOI: 10.1080/19443994.2015.1119737

Montané, D., Torné-Fernández, V., and Fierro, V. (2005). “Activated carbons from lignin: kinetic modeling of the pyrolysis of kraft lignin activated with phosphoric acid," Chemical Engineering Journal 106(1), 1-12. DOI: 10.1016/j.cej.2004.11.001

Suárez-García, F., MartíNez-Alonso, A., and Tascón, J. M. D. (2001). "Porous texture of activated carbons prepared by phosphoric acid activation of apple pulp," Carbon 39(7), 1111-1115. DOI: 10.1016/S0008-6223(01)00053-7 
Snyder, S. A., Adham, S., Redding, A. M., Cannon, F. S., Decarolis, J., and Oppenheimer, J. (2007). "Role of membranes and activated carbon in the removal of endocrine disruptors and pharmaceuticals," Desalination 202(1-3), 156-181. DOI: 10.1016/j.desal.2005.12.052

Srivastava, V. C., Swamy, M. M., Mall, I. D., Prasad, B., and Mishra, I. M. (2006). "Adsorptive removal of phenol by bagasse fly ash and activated carbon: Equilibrium, kinetics, and thermodynamics," Colloids and Surfaces A Physicochemical and Engineering Aspects 272(1), 89-104. DOI: 10.1016/j.colsurfa.2005.07.016

Tan, I. A., Ahmad, A. L., and Hameed, B. H. (2008). "Adsorption of basic dye on highsurface-area activated carbon prepared from coconut husk: Equilibrium, kinetic, and thermodynamic studies," Journal of Hazardous Materials 154(1-3), 337. DOI: 10.1016/j.jhazmat.2007.10.031

Wu, Z., Sun, Y., Hu, L., Xu, N., and Dai, B. L. (2014). "Preparation of activated carbon from formic acid hydrolysis residue by chemical activation of $\mathrm{ZnCl}_{2}$," Advanced Materials Research 860-863, 527-533.

Yadav, A. K., Abbassi, R., Gupta, A., and Dadashzadeh, M. (2013). "Removal of fluoride from aqueous solution and groundwater by wheat straw, sawdust and activated bagasse carbon of sugarcane," Ecological Engineering 52(2), 211-218. DOI: 10.1016/j.ecoleng.2012.12.069

Zhang, R., Zhang, J., Zhang, X., Dou, C., and Han, R. (2014). "Adsorption of congo red from aqueous solutions using cationic surfactant modified wheat straw in batch mode- Kinetic and equilibrium study," Journal of the Taiwan Institute of Chemical Engineers 45(5), 2578-2583. DOI: 10.1016/j.jtice.2014.06.009

Zhu, N., Yan, T., Qiao, J., and Cao, H. (2016). "Synthesis of manganese chloride activated carbon deriving from wheat straw and its adsorption mechanism for arsenic and chromium," International Journal of Environmental Analytical Chemistry 3(1). DOI: $10.4172 / 2380-2391.1000172$

Article submitted: January 21, 2018; Peer review completed: April 13, 2018; Revised version received and accepted: May 13, 2018; Published: May 18, 2018.

DOI: $10.15376 /$ biores.13.3.5204-5212 